\title{
AN AGENT-BASED SIMULATION APPROACH TO MODEL HOSPITAL LOGISTICS
}

\author{
Fragapane, G. I. ; Zhang, C. ${ }^{* *}$; Sgarbossa, F. ${ }^{*} \&$ Strandhagen, J. O.* \\ * Department of Mechanical and Industrial Engineering, NTNU, \\ Norwegian University of Science and Technology, Trondheim, Norway \\ ${ }^{* * *}$ KTH Royal Institute of Technology, Stockholm, Sweden \\ E-Mail: giuseppe.fragapane@ntnu.no, chenzh@kth.se, fabio.sgarbossa@ntnu.no, \\ ola.strandhagen@ntnu.no
}

\begin{abstract}
The increasing rate of hospital admissions has resulted in a commensurate increase in the number of treatments and surgeries performed, as well as resource and material usage, and requires planners to improve hospitals' internal logistics. Logistics modelling of internal goods and corresponding material handling systems and simulating future scenarios can provide planners with necessary decision support. Introducing an agent-based simulation model using historical data generated by an automated guided vehicle (AGV) in a case hospital facilitates analysing the goods delivery system's current status and potential countermeasures to improve internal logistics. In comparison with other industries, such as manufacturing, AGVs utilised in hospitals have to interact with persons, patients and elevators, transport several different types of goods and cover a sizeable multi-floor area. By including these factors, the simulation model represents an appropriate method to test different scenarios and improve delivery performance and AGV utilisation. The study highlights the constraints related to operating AGVs in dynamic environments, such as those encountered in hospitals.

(Received in August 2019, accepted in October 2019. This paper was with the authors 1 month for 1 revision.)
\end{abstract}

Key Words: Logistics, Hospital Logistics, Automated Guided Vehicle, Agent-Based Simulation, Performance Analysis

\section{INTRODUCTION}

Advances in technology and hospital management have helped reduce patients' lengths of stay [1] and introduced new methods for treating patients [2]. The resulting improvements have led to shorter hospitalisations and enabled care providers to treat patients in outpatient or daily clinics instead of hospitalising them for several days. Over the next 20 years, the treatment of somatic patients is expected to increase by about 35-40\% throughout all departments [3]. The increasing hospital admission rate and the commensurate increase in the number of treatments and surgeries performed have also caused increased resource and material usage. This trend can be observed in most Western countries, especially in hospitals located in major cities [4]. Furthermore, the increase in the number of patients has been accompanied by the restructuring and expansion of larger hospitals and closure of smaller hospitals [5]. To provide patient-care services, resources and medical goods must be continuously adapted and managed to meet demand. The increasing pressure caused by increased goods consumption and costs forces hospital practitioners to continually improve and optimise their goods' supply chain and internal hospital logistics.

In a typical hospital, 25-30\% of the budget is spent on the logistics of medical supplies [6]. According to Poulin [7], half of logistics costs can be eliminated with efficient logistics management, and while increasing logistics efficiency might not directly influence patient care, it will afford medical staff more time for patient-related activities [8, 9]. Developing effective and efficient logistics activities can be challenging, considering that the hospital supply chain is usually characterised as highly complex [10]. The external supply chain has been given the most attention in the literature; however, in practice, the internal supply chain 
and internal logistics are the weakest links in the entire chain [8, 11]. Granlund and Wiktorsson [12] argue that the internal supply chain's performance significantly impacts the organisation's overall performance and emphasise the importance of continuous improvement of this segment to achieve competitiveness.

The high degree of flexibility and automation of automated guided vehicles (AGV), compared to other material handling systems, has made it a suitable alternative for goods transportation in hospitals [13]. An AGV can be defined as a driverless transportation system used for the horizontal movement of materials to facilitate flexible material handling [14]. As described in a study by Benzidia et al. [15], AGV systems can automate the flows of pharmaceuticals, catering, laundry and waste on a daily basis in hospitals. While AGVs undergo routine maintenance, the control system and the logistics setup are reviewed and improved less frequently. Recruiting employees with relevant expertise who can further improve hospitals' automated material handling systems and internal logistics is challenging [15]. Hospitals are currently changing significantly to handle the patients of today and the future. Departments are expanded, moved within the hospital or outsourced. These changes affect goods consumption and material flow patterns. Not properly investigating the hospital's logistics and corresponding AGV system on a regular basis can lead to increased vehicle idle times, high material flow peaks, and high variability in transportation and delivery times, which make the entire system less efficient. Most of the literature on how to plan and control AGV systems originate from the manufacturing, warehousing and container terminal industries $[14,16,17]$. The characteristics of these environments have a significant impact on the planning and control of AGV systems. For instance, optimisation studies of flexible manufacturing systems have different requirements and challenges, which lead to different assumptions in comparison to hospitals. Neglecting traffic problems or handling only a single material flow $[18,19]$ makes these models less applicable to hospitals.

In comparison to other industries, AGVs in hospitals must interact with persons, patients and elevators, which have a considerable impact on AGVs' traffic and transportation performance. Furthermore, in hospitals, AGVs transport goods throughout the entire facility and cover a large area, whereas, in an industrial facility, they only cover a limited, small area. Implementing AGVs in hospitals requires adhering to safety standards and ensuring clinical hygiene [20]. AGV use in hospital logistics, in comparison to other industries, remains relatively unexplored, and the complexity of hospital logistics is not adequately considered in current simulation models.

The objective of this study is to investigate the impacts of the hospital environment and AGVs' characteristics on hospital logistics performance. By achieving this objective, the study aims to support hospital planners in continuously improving the material flow in hospitals. The study begins by mapping the AGV system and material flow in a case hospital. Next, since hospitals are a good example of a dynamic environment, we introduce a simulation model for goods transportation by AGVs in hospitals. Finally, several scenarios are simulated to investigate the impact of transporting more goods, lengthening the AGV's operating time, and increasing the number of AGVs and their battery capacity, as well as error reduction. The study supports improving AGVs' picking, delivery and utilisation performance in the case hospital.

\section{THEORETICAL BACKGROUND}

Hospital logistics set the baseline of this study and can be defined as the set of the activities, such as purchasing, inventory management, and transport management, in hospitals to provide and supply goods and services for the overall medical services facilitating patient care [21]. Hospital logistics requires handling the complexity of the hospital system to provide supplies 
for physicians and a clientele with a particular variability and unpredictability profile and enable both planned and ad hoc treatments [22]. Some medical goods cannot be sent just-intime from the suppliers for treatment at the point-of-care. Many storerooms are spread throughout a hospital complex, stocking the medical supplies, clothes, laundry and related items for nurses and physicians. The distribution of pharmaceuticals, office supplies, food, maintenance, cleaning, sterilisation, linen and waste further complicates the transportation network in a hospital [5].

Modelling and simulation are methodologies applied to study logistics systems in hospitals and provide necessary decision support. An extensive review by Volland et al. [8] finds that few publications on modelling the material flow in hospitals have been published. The main focus of this literature is on optimising flows of goods for pharmaceuticals, laundry and medical supplies, as well as bed-related goods, with the objective of minimising work routes, workloads and costs. Routing, scheduling and material management system issues are mainly discussed in these publications. Furthermore, only a few studies investigate the material handling or delivery methods in hospitals [8]. A study conducted by Rimpiläinen and Koivo [23] models and simulates a manual truck delivery system for hospitals. The authors investigate the scheduling of meal transportation, and the impact of a number of drivers of transportation capacity are analysed.

Discrete-event simulation is commonly used to design and validate AGV systems in hospitals $[24,25]$. Simulation models are used to conduct a series of simulation experiments with the goal of minimising the required vehicle fleet size or maximising resource utilisation. From these simulations, information can be derived for transportation scheduling, system queueing and transportation performance. However, these simulation models do not account for several crucial factors, such as battery management. Numerous models and simulations can be found in other industries to design and define an AGV system. However, these models do not consider hospitals-specific characteristics and factors.

Evaluation studies conducted in hospitals $[26,27]$ using stochastic models mainly seek to optimize patient logistics rather than the flow of goods. Interventions for sources of uncertainty are discussed in these simulation-based studies; however, again, very few discussions address the interdependency of the dynamic system and, especially, the automated material handling infrastructure to evaluate technologies in service systems.

Mixed methods research with simulation as the core of the framework is used for healthcare management, but its use remains somewhat underdeveloped in hospitals' internal logistics management. Zhang et al. [28] observe that although simulation studies of certain types of material flow in hospital environments have been performed, evidence-based on validated simulation models, as well as guidelines for selecting the right parameters and inputs when building logistical simulation models, is largely lacking.

None of these studies, however, investigate factors affecting material handling systems in hospitals or include a dynamic environment in the models. To the best of our knowledge, the existing literature is lacking in this regard. To bridge this gap, this research combines quantitative and qualitative approaches to model and simulate the material flow performed by AGVs and investigate how managers can solve their hospital's internal logistics problems.

\section{METHOD}

This research used a mixed-methods approach that combines qualitative and quantitative methods to strengthen the results' credibility and generalisability. The research design consists of an in-depth case study and agent-based simulation model of the case hospital using historical AGV data. Observations and semi-structured interviews were conducted to identify the hospital's logistics problems and the main factors affecting the AGV system. Based on the 
findings of the case study and internal logistics information gathered, an agent-based simulation model was developed and introduced. This method is new in operations research and often overlooked as researchers have tended to rely on more traditional methods [29]. Agent-based simulation (ABS) has garnered more interest among practitioners because it can model stochastic processes. At its core, ABS is built by autonomous resource units that follow a series of predefined rules to achieve their objectives whilst interacting with each other and their environment [29, 30]. These attributes are especially interesting since the hospital environment should be integrated to a higher degree in the models. Interactions between AGVs and personnel or elevators can be included in the simulation model. A previous study has shown that ABS is especially useful in simulating complex logistics networks and understanding real-world systems in which representing or modelling many individual units is important $[31,32]$. ABS is especially suitable for this study in modelling and simulating the hospital's logistics with the different individual units and evaluating the transportation system.

Case selection is a vital part of the research process. Our strategy is based on achieving theoretical replication and using an information-rich case to produce contrary results and maximum variation but for predictable reasons. This research is based on a single hospital. Hospitals can differ greatly from each other in layout and services provided. However, the selected case hospital represents a major university hospital and has all the departments common to hospitals, a capacity of 850 beds and, currently, more than 8,000 employees; it also relies heavily on an automated transportation system for internal logistics. Several hospitals using AGV systems with a similar setup for material handling have been studied in the literature [13].

AGV data collected from the internal material transportation system between January 2017 and the end of December 2018 were used to feed the simulation model. The data included details of AGV jobs, AGV battery information, errors and elevator information. The model and simulation results were presented and discussed in iterative loops with the case hospital's logistics managers and maintenance personnel. The feedback was utilised to improve the simulation model.

\section{CASE DESCRIPTION}

The logistics network consists of goods arrival and several in-house productions, including catering and sterile processing services, as well as departments, such as the wards, operating theatre and points-of-care. Several transportation methods can be applied when moving goods within a hospital. As stated by the hospital managers, most of the goods are transported by the AGVs. This implies the material flow of food, sterile goods, laundry, goods delivered from the central warehouse, pharmaceuticals and waste. The goods that have to be transported are packed onto wagons and placed at pick/delivery (P/D) stations, where radio-frequency identification tags transmit information regarding the order and delivery destination to the AGV control system. The AGV system is operated via a centralised structure, and jobs are dispatched to the nearest AGV to reduce the AGVs' idle time. The hospital has integrated a radio frequency communication system that allows AGVs to open doors and call elevators. Using connecting tunnels between different buildings and elevators, AGVs can access, to a considerable extent, the entire hospital. In each building, they can access up to six different floors. When a wagon arrives at its final destination, the AGV system sends an arrival message to the department. The wagon and goods are moved from the P/D station to the department manually. To initiate the return transportation of a wagon, the wagon has to be placed at a P/D station. 
An influence diagram was used to map both the interactions of the various elements of the decision setting and the transportation tasks performed by the AGVs (Fig. 1).

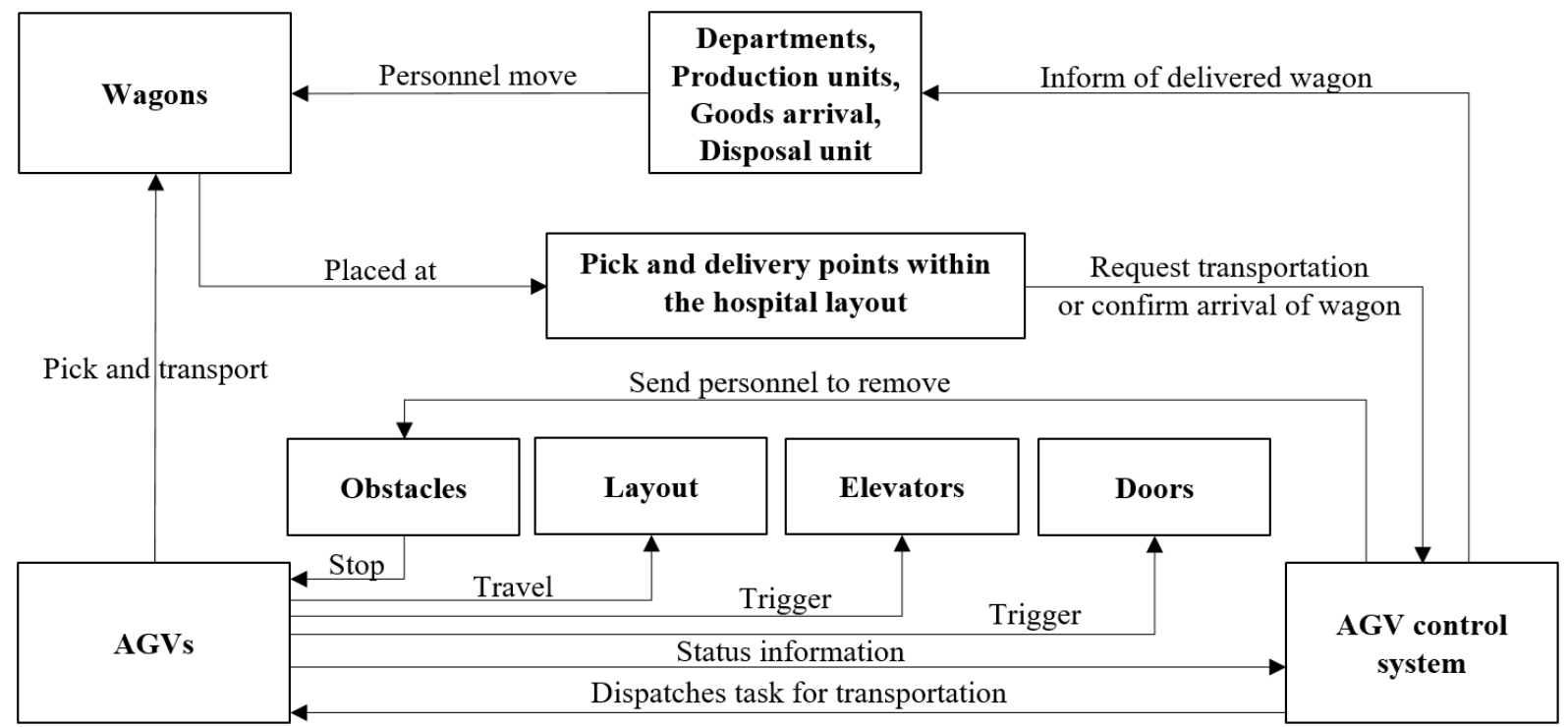

Figure 1: Influence diagram showing interactions within the transportation network.

AGVs lift and move wagons along the $4500 \mathrm{~m}$ guide-path. Currently, the AGV system consists of 21 laser-guided AGVs transporting approximately 50-70 tons of goods per week among 114 P/D stations distributed across the hospital.

\section{SIMULATION MODEL ARCHITECTURE}

\subsection{Model assumptions}

The assumptions made to facilitate model development are listed below:

- Departments with medical units generally require more supplies and transportation services than the hospital's supporting units.

- The transportation schedule is set for at least 12 hours of work per day with possible extensions or reductions.

- An infinite number of wagons are available to be packed.

- Only one AGV can access and use an elevator at a time.

- AGVs can operate bi-directionally in $40 \%$ of the corridors.

- AGVs charge their batteries between transportation orders and, in most cases, access a charging station.

\subsection{Material flow simulation modelling in hospital environments}

The selected hospital serves as the reference system and the empirical sources for exploring the impact of resource configurations in the management of material flow. The hospital's logistics managers identified eight departments needing material delivery services: the emergency and cardiothoracic centre, the administration centre, the laboratory centre, the neuro centre, the knowledge centre, the mobility centre and the gastro centre. The departments are located in different areas of the hospital. Each department has unique demand patterns. Populating the simulation environment enabled obtaining a process-oriented structure in which asynchronous agents exist, as shown in Fig. 2. The process simulation represents material flow handling in the reference system, with the following fundamental logic of high fidelity to the investigative system: 
1. Goods arrive at a department (i.e., a local department or the supply centre) as the sender.

2. A processing slot is assigned, and a staff member prepares the goods to send.

3. The staff return available when the preparing job is finished, after which the nearest available AGV with an adequate energy supply is assigned to pick the goods.

4. The AGV picks up the goods and navigates through the hospital network towards the destination department, which is pre-defined by the sender.

5. The AGV delivers and unloads the goods at a slot at the destination department.

6 . The goods are received by a staff member at the destination department.

7. The unloaded AGV returns available and to the pre-defined cruising mode.

The arrival rate tables are specified for the hospital centres. These specifications are performed inside the arrival module according to historical data regarding item types, hourly rates, item senders and receivers. The simulation model couples the agent-based sub-models and a discrete-event simulation model. The steering agents are containers and AGVs, operating according to the logistics processes, which include sending and receiving goods, as well as battery charging for the AGVs. These processes are recreated by the discrete-event simulation as the living environment of the agents. Meanwhile, metrics can be obtained and automatically updated with information provided by asynchronous agents. By doing so, it was able to obtain the following metrics for the validation of a baseline scenario, enabling a simulation-based evaluation and prediction of the logistics system:

- arrival and discharge patterns of goods;

- performance of picking, delivery and utilisation of AGV vehicles.
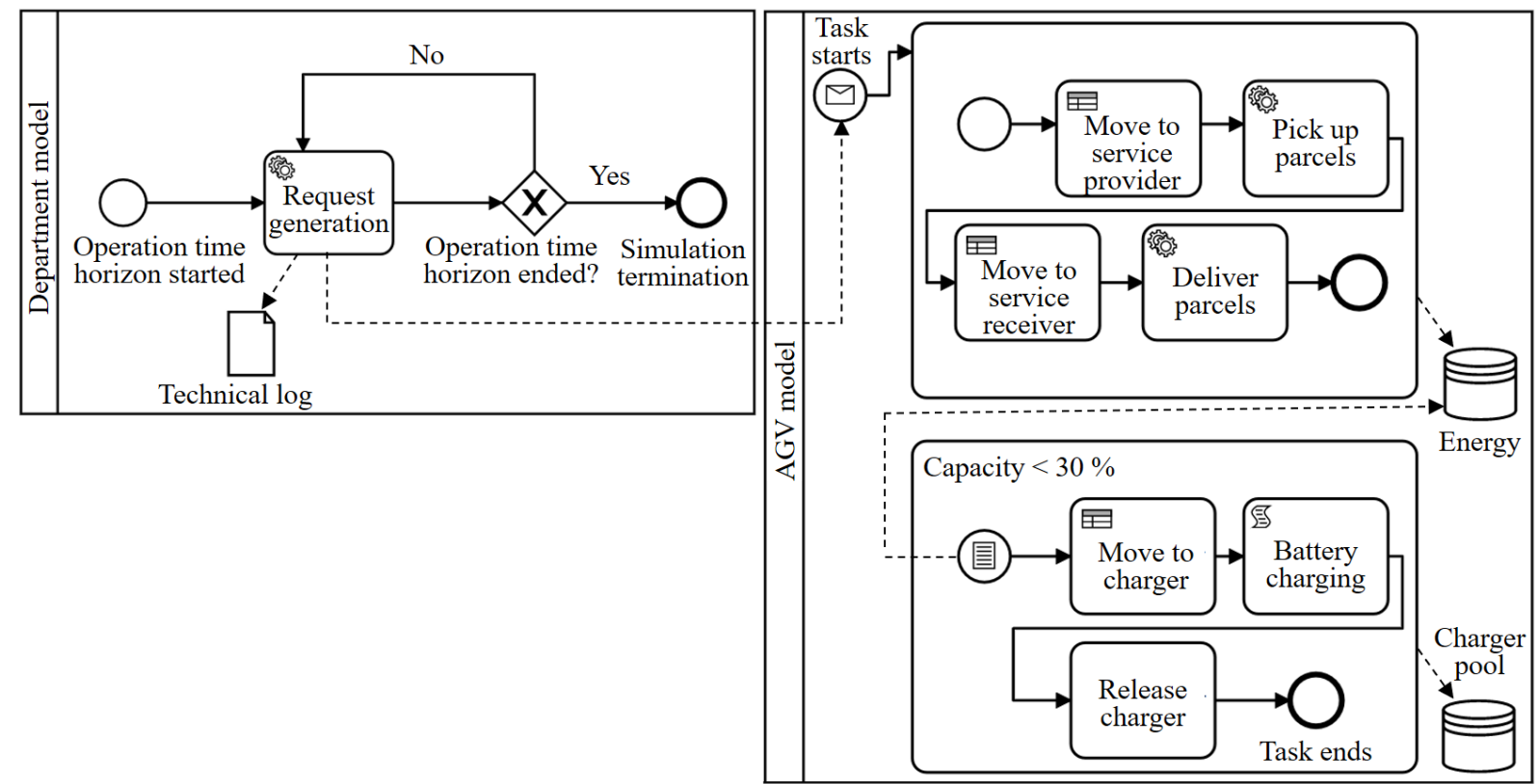

Figure 2: Architecture of the simulation model.

An observation of the system shows that the battery discharge rate depends on the weight of the load carried by the AGV and the distance travelled. To ensure maximum availability, the vehicle manufacturer aims to maintain the battery system at a state of charge from 50 to $80 \%$. This means that when not in service, the AGVs are directed to charge as often as possible, even if they charge for only a few minutes. The 100 A charge current will recharge around one-third of the battery modules' capacity in less than 20 minutes. Given these details, a critical consideration, when operating AGV transport systems, is recharging, since the vehicles are powered by batteries and require on-hold and charging processes in autonomous states. Agent-based modelling is highly appropriate for modelling such robotic and proactive 
actors because of its ease of interacting with a circulative system. In agent-based modelling, AGVs are modelled as a collection of autonomous decision-making ownership entities. Each agent individually assesses the energy consumption situation and triggers behaviours according to pre-defined criteria. The model is validated on the micro-level since the construction is based on observational data, historical data and existing flowcharts.

\subsection{Modelling material handling processes}

The Weibull distribution is ideal for modelling the processes of AGVs picking up goods and delivering them to a receiver, as Table I summarises. To seek the best fit based on the collected data, the Kolmogorov-Smirnov test for distribution was used, which is widely used to simulate industrial processes. Weibull, exponential, gamma, logistic, normal and lognormal distributions were tested. The distribution with a minimised square error was selected. The quality test determined that all of the parameter estimations of the selected distributions were significant with corresponding $p$-values less than 0.05 , while the Weibull distribution was suitable for modelling the material handling behaviours.

Table I: Service duration modelling (in minutes).

\begin{tabular}{|c|c|c|c|c|c|}
\hline Process & $\begin{array}{c}\text { Sample } \\
\text { size }\end{array}$ & Mean & $\begin{array}{c}\text { Standard } \\
\text { deviation }\end{array}$ & Distribution formulation & $\begin{array}{c}\text { Parameter } \\
\text { significance } \boldsymbol{t} \text {-test }\end{array}$ \\
\hline Picking & 151306 & 15.7 & 14.2 & Weibull $(\lambda=167.9 ; k=1.2)^{*}$ & $p<0.05$ \\
\hline Delivery & 151306 & 12.3 & 8.8 & Weibull $(\lambda=13.9 ; k=1.6)^{*}$ & $p<0.05$ \\
\hline
\end{tabular}

\section{RESULTS}

\subsection{Simulation model verification and validation}

Model verification and validation are performed to ensure reliable projections, which are an important characteristic of simulations in logistical applications. The validation of an ABS model for future scenarios is particularly challenging for simulation projects of future designs and scenarios given that the system's mechanical computation might neglect behavioural aspects. Therefore, as a non-statistical validation technique, participatory simulation is considered appropriate and has been used to endorse the simulated environment of a logistics system [33].

No discrepancies regarding entity movements were found because the simulation model recreated the processes and asynchronous agents. All the AGVs are docked in charging slots when not engaged in transporting orders. The AGVs and containers that are currently involved in relevant simulation building blocks are visualised on the interface. It can be observed that containers are transported from the sender to the receiver with necessary resource attachments. These resource attachments are personnel supports and are moved by transporters. The arrival of orders follows the daily pattern.

The model was implemented using the simulation software AnyLogic. Special attention was devoted to validating the model to ensure that the simulation outputs are adequately represented in the system under investigation. One-year steady-state results, based on 80 independent and identically distributed replications (with different random seeds) and a warm-up period of three months, were determined. Validation was based on a Student's $t$-test comparing the empirical and average simulated results of the monthly supply and disposals. The null hypothesis ( $\mathrm{H} 0)$ was tested under a probability of rejecting the model at the $\alpha=0.01$ level. The corresponding critical values of the test were $t(48,0.99) \approx 2.40, t(49,0.99) \approx 2.40$, $t(50,0.99) \approx 2.40, t(51,0.99) \approx 2.40$. Table II reports the statistical test results for each month and material group. The results indicate the model's ability to represent the real system. 
Table II: Student's $t$-test results for sterile throughput.

\begin{tabular}{|c|c|c|c|c|c|c|c|c|}
\cline { 2 - 10 } \multicolumn{1}{c|}{} & \multicolumn{4}{c|}{ Supply transportation } & \multicolumn{3}{c|}{ Return transportation } \\
\hline $\begin{array}{c}\text { Day of } \\
\text { week }\end{array}$ & $\begin{array}{c}\text { Real } \\
\text { value }\end{array}$ & $\begin{array}{c}\text { Average } \\
\text { simulated } \\
\text { output }\end{array}$ & Diff. & $t$-test & $\begin{array}{c}\text { Real } \\
\text { value }\end{array}$ & $\begin{array}{c}\text { Average } \\
\text { simulated } \\
\text { output }\end{array}$ & Diff. & $t$-test \\
\hline Monday & 283 & 280 & -3 & 0.51 & 290 & 282 & -8 & 1.62 \\
\hline Tuesday & 268 & 260 & -8 & 1.84 & 296 & 287 & -9 & 2.03 \\
\hline Wednesday & 264 & 271 & 7 & -1.55 & 296 & 300 & 4 & -0.82 \\
\hline Thursday & 254 & 246 & -8 & 1.79 & 293 & 282 & -11 & 2.02 \\
\hline Friday & 270 & 279 & 9 & -2.00 & 297 & 290 & -7 & 1.36 \\
\hline
\end{tabular}

The focus was on the average throughput for each hour of the workday for transported wagons, which was one of the most relevant measures to evaluate and coordinate the allocation of resources throughout the day with the demand profile. Breaking down this datum into daily dynamics, Fig. 3 shows how this throughput varied throughout the workweek. By making changes in department modules, the user can directly level the transportation and then predict the demand profile, which is a challenging part of the current logistics operation.

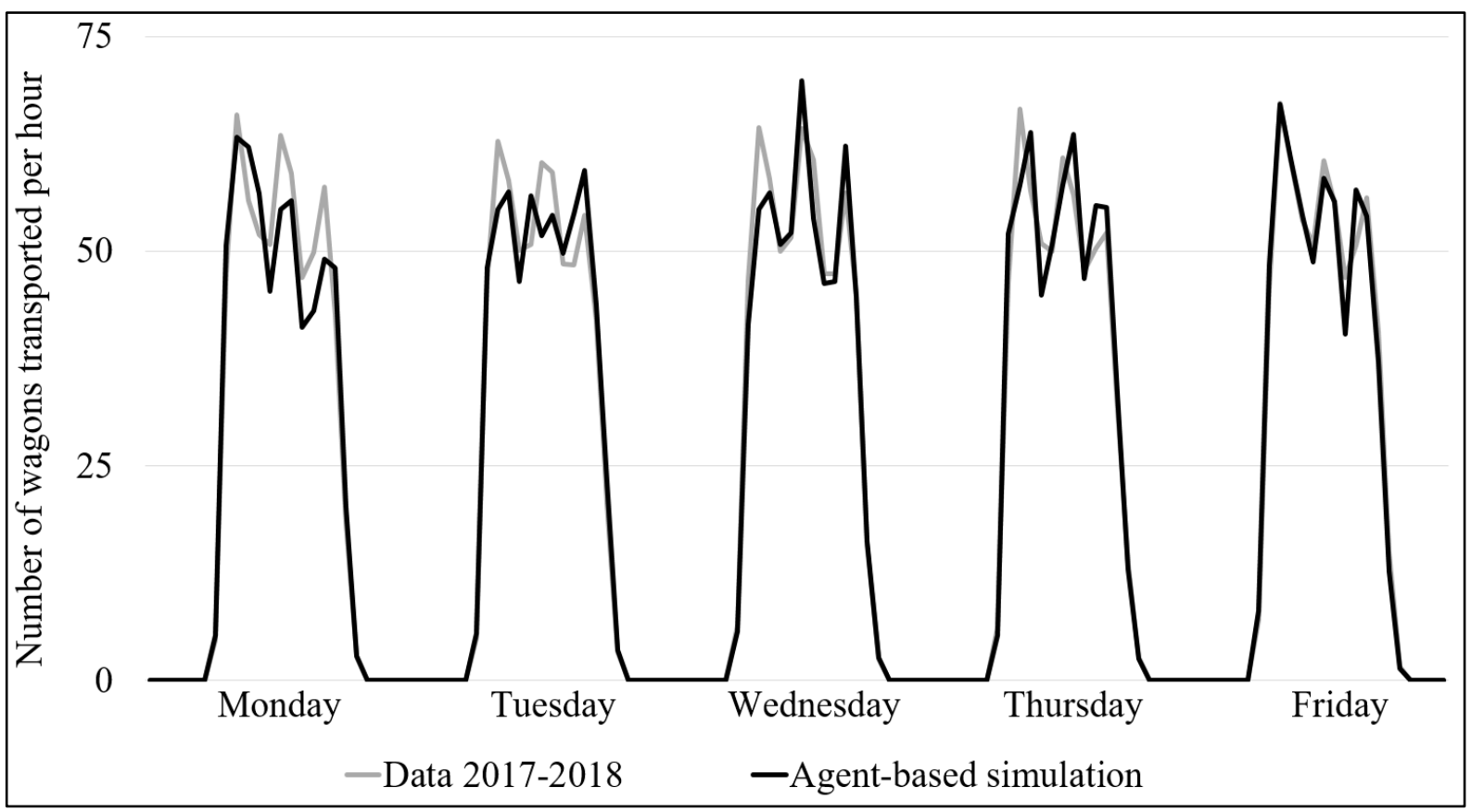

Figure 3: A comparison of historical AGV data and ABS results.

\subsection{Simulation-based system evaluation}

The impact of increased goods transportation and the impact of implementing different countermeasures were simulated to study the current status and future challenges. The countermeasures included levelling transportation, increasing the reliability of delivery operations, and increasing the transportation capacity. Levelling transportation can minimise the transportation peaks and shorten the AGVs' response time. Therefore, investigating which material flows can be transported outside of the high-traffic hours and how the AGV transportation schedule might have to be adapted were considered relevant. By expanding the AGVs' operating time and adapting the transportation schedule, different single-material flow patterns could be varied and simulated to analyse their impact on delivery performance.

The reliability of current delivery operations has been criticised by the case hospital's logistics managers. The dynamic environment clearly stresses the AGV system, leading to 
material flow disturbances and longer waiting times. The AGVs use and share corridors and elevators with personnel, patients and visitors, which affect delivery performance. AGVs cannot avoid persons or obstacles by going around them. The maintenance operators have to remove obstacles from in front of the AGVs several times a day. The guide paths of the AGVs are unknown to visitors or those who are unfamiliar with the hospital. Parked wheelchairs or other items on the guide path can cause queues and delays. Therefore, different adaptions to the guide path in high traffic areas and obstacle avoidance scenarios were investigated and simulated.

Lastly, the effects of increased transportation capacity have been investigated. Varying vehicle properties, such as the type or number of vehicles, the battery, and transportation load, might influence the AGV system's performance. Alternatives regarding the number of vehicles and battery management were further examined in this study since they were identified as most relevant by the logistics managers.

Using the ABS, the performance of picking, delivery and utilisation were determined to evaluate the different approaches. The following tables show some of the results of the different investigations.

Table III: Impact of increased goods transportation.

\begin{tabular}{|c|c|c|c|c|c|c|c|}
\cline { 2 - 8 } \multicolumn{1}{c|}{} & $\mathbf{0 \%}$ & $\mathbf{5 \%}$ & $\mathbf{1 0} \%$ & $\mathbf{1 5} \%$ & $\mathbf{2 0} \%$ & $\mathbf{2 5} \%$ & $\mathbf{3 0} \%$ \\
\hline Picking & $15.7 \mathrm{~min}$ & $15.8 \mathrm{~min}$ & $15.9 \mathrm{~min}$ & $16.0 \mathrm{~min}$ & $16.2 \mathrm{~min}$ & $19.0 \mathrm{~min}$ & $23.4 \mathrm{~min}$ \\
\hline Delivery & $12.3 \mathrm{~min}$ & $12.3 \mathrm{~min}$ & $13.2 \mathrm{~min}$ & $13.3 \mathrm{~min}$ & $13.4 \mathrm{~min}$ & $15.2 \mathrm{~min}$ & $18.4 \mathrm{~min}$ \\
\hline Utilisation & $63.3 \%$ & $66.3 \%$ & $69.7 \%$ & $72.9 \%$ & $79.1 \%$ & $85.2 \%$ & $92.8 \%$ \\
\hline
\end{tabular}

Table IV: Impact of expanding the operating time.

\begin{tabular}{|c|c|c|c|c|c|c|}
\cline { 2 - 7 } \multicolumn{1}{c|}{} & $\mathbf{0 \%}$ & $\mathbf{5 \%}$ & $\mathbf{1 0} \%$ & $\mathbf{1 5} \%$ & $\mathbf{2 0} \%$ & $\mathbf{2 5} \%$ \\
\hline Picking & $15.7 \mathrm{~min}$ & $15.1 \mathrm{~min}$ & $15.1 \mathrm{~min}$ & $15.2 \mathrm{~min}$ & $14.9 \mathrm{~min}$ & $14.9 \mathrm{~min}$ \\
\hline Delivery & $12.3 \mathrm{~min}$ & $11.9 \mathrm{~min}$ & $12.0 \mathrm{~min}$ & $11.8 \mathrm{~min}$ & $11.7 \mathrm{~min}$ & $11.7 \mathrm{~min}$ \\
\hline Utilisation & $63.3 \%$ & $51.3 \%$ & $46.8 \%$ & $38.0 \%$ & $30.3 \%$ & $29.1 \%$ \\
\hline
\end{tabular}

Table V: Impact of increasing the number of vehicles.

\begin{tabular}{|c|c|c|c|c|c|c|}
\cline { 2 - 7 } \multicolumn{1}{c|}{} & $\mathbf{0 \%}$ & $\mathbf{5 \%}$ & $\mathbf{1 0} \%$ & $\mathbf{1 5 \%}$ & $\mathbf{2 0} \%$ & $\mathbf{2 5} \%$ \\
\hline Picking & $15.7 \mathrm{~min}$ & $14.1 \mathrm{~min}$ & $13.3 \mathrm{~min}$ & $12.9 \mathrm{~min}$ & $12.8 \mathrm{~min}$ & $12.8 \mathrm{~min}$ \\
\hline Delivery & $12.3 \mathrm{~min}$ & $11.1 \mathrm{~min}$ & $10.2 \mathrm{~min}$ & $10.1 \mathrm{~min}$ & $9.8 \mathrm{~min}$ & $9.8 \mathrm{~min}$ \\
\hline Utilisation & $63.3 \%$ & $51.3 \%$ & $47.5 \%$ & $48.1 \%$ & $46.8 \%$ & $44.4 \%$ \\
\hline
\end{tabular}

Table VI: Impact of increased battery capacity.

\begin{tabular}{|c|c|c|c|c|}
\hline & $0 \%(\sim 3 h)$ & $100 \%(\sim 6 h)$ & $200 \%(\sim 9 h)$ & $300 \%(\sim 12 h)$ \\
\hline Picking & $15.7 \mathrm{~min}$ & $12.9 \mathrm{~min}$ & $12.6 \mathrm{~min}$ & $12.5 \mathrm{~min}$ \\
\hline Delivery & $12.3 \mathrm{~min}$ & $10.4 \mathrm{~min}$ & $10.5 \mathrm{~min}$ & $10.4 \mathrm{~min}$ \\
\hline Utilisation & $63.3 \%$ & $53.8 \%$ & $49.5 \%$ & $49.1 \%$ \\
\hline
\end{tabular}

Table VII: Impact of deadlock, obstacle avoidance and error reduction.

\begin{tabular}{|c|c|c|c|c|c|c|}
\cline { 2 - 7 } \multicolumn{1}{c|}{} & $\mathbf{0 \%}$ & $\mathbf{5 \%}$ & $\mathbf{1 0} \%$ & $\mathbf{1 5 \%}$ & $\mathbf{2 0} \%$ & $\mathbf{2 5} \%$ \\
\hline Picking & $15.7 \mathrm{~min}$ & $12.3 \mathrm{~min}$ & $11.5 \mathrm{~min}$ & $10.8 \mathrm{~min}$ & $9.7 \mathrm{~min}$ & $9.6 \mathrm{~min}$ \\
\hline Delivery & $12.3 \mathrm{~min}$ & $10.4 \mathrm{~min}$ & $9.7 \mathrm{~min}$ & $8.5 \mathrm{~min}$ & $8.0 \mathrm{~min}$ & $8.0 \mathrm{~min}$ \\
\hline Utilisation & $63.3 \%$ & $56.3 \%$ & $50.6 \%$ & $45.6 \%$ & $40.5 \%$ & $40.4 \%$ \\
\hline
\end{tabular}

\section{DISCUSSION AND CONCLUSION}

Different scenarios were simulated to analyse various improvement approaches, including levelling the transportation volume, increasing the reliability of delivery operations and increasing transportation capacity, to address the increasing demand for transported goods in 
the hospital. In the previous chapter, the most important results were presented. Based on insights gained from the simulation, hospital planners can evaluate forecasted needs and countermeasures. Different potential solutions were tested to determine how these changes impact the logistics and material handling system. The results indicate a non-linear progression, which can be helpful in recognising the limits and boundaries of the implemented material handling system.

The increase in goods transportation affected the AGV system' performance slightly until the tipping point at $25 \%$, with a continuous, strong increase afterwards (see Table III). The case hospital's AGV system has been designed to meet not only current demand but also handle future transportation demand to some extent. However, the evaluation of the logistics system shows that after $20 \%$, a strong performance loss can be expected in the robustness of the system. Small demand changes, at this point, can have a stronger impact. To address this challenge, different alternatives were investigated. Expanding operating hours has a small effect on performance because the transportation demand pattern has high peaks during the hospital's core activity hours, and many transportation activities cannot be allocated outside of these hours. For instance, food cannot be served early in the morning or at night. Increasing the number of AGVs and their battery capacity are two alternatives with potential for improvement. It was observed that without increasing the number of elevators, the increased AGV capacity quickly reached its limits (see Tables III and V). In these cases, bottlenecks develop at or in the elevators and cause queues, resulting in minimal further performance improvement.

Queues with AGVs can lengthen quickly in hospitals and affect the logistics system. If a queue lengthens, several AGVs are quickly affected. The hospital layout and corridors do not allow for several routing alternatives. Obstacles hindering the AGVs' movements or the maintenance team taking a long time to correct errors have a significant impact on the AGVs' transportation performance. Of the average of 60-100 errors counted per day by the case hospital's AGV system, only a few lead to very long queues forming. Improvement efforts undertaken to reduce errors and, thus, avoid queues, can significantly reduce transportation times (see Table VII).

This study has highlighted constraints related to operating AGVs in dynamic environments. The simulation model uses and relies on historical data obtained from the AGV system, which contains a considerable amount of information representing the 'real' material flow. Compared to other industries, in hospitals, enterprise resource planning systems or tracking systems are less common and less integrated. The ABS approach enables depicting on the current and modified material flows. The validation of the simulation model achieved good results, further emphasising the relevance of our approach. One of the strengths of this simulation model is that it can investigate goods that usually have limited information available, such as catering or waste. Single material flow can be further investigated and analysed.

The model can be easily adapted for use in other hospitals and can take several additional inputs into consideration; hence, it can be used to evaluate the implementation of new or different material handling systems. Furthermore, according to the hospital managers and the results of the simulation, AGVs are sensitive to the dynamic environments found in hospitals. In recent years, technological advances have been rapid and influenced the indoor mobility of robots. Increased battery power, cameras for high-quality environment recognition, and increased on-board computational power have enabled greater autonomy in mobile robots' navigation. Obstacle avoidance and dynamic pathfinding make autonomous mobile robots more appropriate for dynamic environments, such as hospitals. However, this kind of material handling system is still not widely applied and investigated in hospitals. 
Future research should investigate the benefits and boundaries of autonomous mobile robots in hospitals to promote the use of this innovative technology. Additionally, the applicability of this simulation model should be explored in other hospitals, and its effects on the material handling system's long-term performance should be investigated.

\section{ACKNOWLEDGEMENT}

This research received funding from the strategic research area NTNU Health in 2019 at NTNU, Norwegian University of Science and Technology, the environment and sustainable development project (number VDLA04) and Jubileumsanslaget grant (grant number V-2019-0611/1) at KTH, Royal Institute of Technology. The authors also gratefully acknowledge the case hospital that made it possible to conduct this study.

\section{REFERENCES}

[1] Williams, C.; Asi, Y.; Raffenaud, A.; Bagwell, M.; Zeini, I. (2016). The effect of information technology on hospital performance, Health Care Management Science, Vol. 19, No. 4, 338-346, doi: $10.1007 / \mathrm{s} 10729-015-9329-\mathrm{z}$

[2] Barbash, G. I.; Glied, S. A. (2010). New technology and health care costs-the case of robotassisted surgery, The New England Journal of Medicine, Vol. 363, No. 8, 701-704, doi:10.1056/NEJMp1006602

[3] St. Olavs Hospital HF. Utviklingsplan 2019-2035 (February 2018). 39 pages, from https://stolav.no/Documents/Utviklingsplan/Vedtatt\%20Utviklingsplan\%20220218.pdf, accessed on 30-06-2019

[4] OECD/EU. (2018). Health at a Glance: Europe 2018: State of Health in the EU Cycle, OECD Publishing, Paris

[5] Giancotti, M.; Guglielmo, A.; Mauro, M. (2017). Efficiency and optimal size of hospitals: results of a systematic search, Plos One, Vol. 12, No. 3, Paper e0174533, doi:10.1371/ journal.pone. 0174533

[6] Ozcan, Y. A. (2005). Quantitative Methods in Health Care Management: Techniques and Applications, Jossey-Bass, San Francisco

[7] Poulin, É. (2003). Benchmarking the hospital logistics process: a potential cure for the ailing health care sector, CMA Management, Vol. 77, No. 1, 20-23

[8] Volland, J.; Fügener, A.; Schoenfelder, J.; Brunner, J. O. (2017). Material logistics in hospitals: a literature review, Omega, Vol. 69, 82-101, doi:10.1016/j.omega.2016.08.004

[9] Jarrett, P. G. (1998). Logistics in the health care industry, International Journal of Physical Distribution Logistics Management, Vol. 28, No. 9-10, 741-772, doi:10.1108/ $\underline{09600039810248154}$

[10] Rivard-Royer, H.; Landry, S.; Beaulieu, M. (2002). Hybrid stockless: a case study, International Journal of Operations \& Production Management, Vol. 22, No. 4, 412-424, doi:10.1108/ 01443570210420412

[11] Landry, S.; Philippe, R. (2004) How logistics can service healthcare, Supply Chain Forum: An International Journal, Vol. 5, No. 2, 24-30, doi:10.1080/16258312.2004.11517130

[12] Granlund, A.; Wiktorsson, M. (2014). Automation in internal logistics: strategic and operational challenges, International Journal of Logistics Systems and Management, Vol. 18, No. 4, 538558, doi:10.1504/IJLSM.2014.063984

[13] Ullrich, G. (2015). Automated Guided Vehicle Systems: A Primer with Practical Applications, Springer-Verlag, Berlin, doi:10.1007/978-3-662-44814-4

[14] Vis, I. F. A. (2006). Survey of research in the design and control of automated guided vehicle systems, European Journal of Operational Research, Vol. 170, No. 3, 677-709, doi:10.1016/j.ejor.2004.09.020

[15] Benzidia, S.; Ageron, B.; Bentahar, O.; Husson, J. (2018). Investigating automation and AGV in healthcare logistics: a case study based approach, International Journal of Logistics Research and Applications, Vol. 22, No. 3, 273-293, doi:10.1080/13675567.2018.1518414 
[16] Le-Anh, T.; De Koster, M. B. M. (2006). A review of design and control of automated guided vehicle systems, European Journal of Operational Research, Vol. 171, No. 1, 1-23, doi:10.1016/j.ejor.2005.01.036

[17] Bechtsis, D.; Tsolakis, N.; Vlachos, D.; Iakovou, E. (2017). Sustainable supply chain management in the digitalisation era: the impact of automated guided vehicles, Journal of Cleaner Production, Vol. 142, No. 4, 3970-3984, doi:10.1016/j.jclepro.2016.10.057

[18] Udhayakumar, P.; Kumanan, S. (2010). Task scheduling of AGV in FMS using non-traditional optimization techniques, International Journal of Simulation Modelling, Vol. 9, No. 1, 28-39, doi:10.2507/IJSIMM09(1)3.139

[19] Mousavi, M.; Yap, H. J.; Musa, S. N.; Dawal, S. Z. M. (2017). A fuzzy hybrid GA-PSO algorithm for multi-objective AGV scheduling in FMS, International Journal of Simulation Modelling, Vol. 16, No. 1, 58-71, doi:10.2507/IJSIMM16(1)5.368

[20] Pedan, M.; Gregor, M.; Plinta, C. (2017). Implementation of automated guided vehicle system in healthcare facility, Procedia Engineering, Vol. 192, 665-670, doi:10.1016/j.proeng.2017.06.115

[21] Dembińska-Cyran, I. (2005). Internal and external supply chain of hospital, LogForum, Vol. 1, No. 5, 7 pages

[22] Wieser, P. (2011). From health logistics to health supply chain management, Supply Chain Forum: An International Journal, Vol. 12, No. 1, 4-13, doi:10.1080/16258312.2011.11517249

[23] Rimpiläinen, T. I.; Koivo, H. (2008). Modeling and simulation of hospital material flows, Proceedings of the $10^{\text {th }}$ International Conference on Computer Modelling and Simulation, 579583, doi:10.1109/UKSIM.2008.44

[24] Čerić, V. (1990). Simulation study of an automated guided-vehicle system in a Yugoslav hospital, Journal of the Operational Research Society, Vol. 41, No. 4, 299-310, doi:10.1057/jors.1990.51

[25] Swain, R. W.; John III, M. J. (1978). A simulation analysis of an automated hospital materials handling system, AIIE Transactions, Vol. 10, No. 1, 10-18, doi:10.1080/05695557808975178

[26] Chockalingam, A.; Jayakumar, K.; Lawley, M. A. (2010). A stochastic control approach to avoiding emergency department overcrowding, Proceedings of the 2010 Winter Simulation Conference, 2399-2411, doi:10.1109/WSC.2010.5678936

[27] Hagtvedt, R.; Ferguson, M.; Griffin, P.; Jones, G. T.; Keskinocak, P. (2009). Cooperative strategies to reduce ambulance diversion, Proceedings of the 2009 Winter Simulation Conference, 1861-1874, doi:10.1109/WSC.2009.5429194

[28] Zhang, C.; Grandits, T.; Härenstam, K. P.; Hauge, J. B.; Meijer, S. (2018). A systematic literature review of simulation models for non-technical skill training in healthcare logistics, Advances in Simulation, Vol. 3, No. 15, doi:10.1186/s41077-018-0072-7

[29] Maidstone, R. (2012). Discrete event simulation, system dynamics and agent based simulation: discussion and comparison, Report, 6 pages, Lancaster University, Lancaster

[30] Wurzer, G. (2013). In-process agent simulation for early stages of hospital planning, Mathematical and Computer Modelling of Dynamical Systems, Vol. 19, No. 4, 331-343, doi: $10.1080 / 13873954.2012 .761638$

[31] Siebers, P. O.; Macal, C. M.; Garnett, J.; Buxton, D.; Pidd, M. (2010). Discrete-event simulation is dead, long live agent-based simulation!, Journal of Simulation, Vol. 4, No. 3, 204-210, doi: $10.1057 /$ jos.2010.14

[32] Zhao, J. Y.; Wang, Y. J.; Xi, X.; Wu, G. D. (2017). Simulation of steel production logistics system based on multi-agents, International Journal of Simulation Modelling, Vol. 16, No. 1, 167-175, doi:10.2507/IJSIMM16(1)CO4

[33] Anand, N.; Meijer, D.; van Duin, J. H. R.; Tavasszy, L.; Meijer, S. (2016). Validation of an agent based model using a participatory simulation gaming approach: the case of city logistics, Transportation Research Part C: Emerging Technologies, Vol. 71, 489-499, doi:10.1016/j.trc.2016.08.002 